\title{
A Year Emergence of Covid-19 in Nigeria and Its Consequences on Educational Development of Kwara State
}

\author{
Dr. Tajudeen Niyi Madandola ${ }^{1}$, Omotayo Salawu ${ }^{2}$, Sherif Niyi Sakariyau ${ }^{3}$, Oyebola \\ Oyekemi Owolabi ${ }^{4}$, Monsurat Oluwabukola Madandola ${ }^{5}$ \\ ${ }^{1,2,3}$ Department of Computer Science, Kwara State College of Education, Oro Nigeria \\ ${ }^{4}$ Department of History, Kwara State College of Education, Oro Nigeria \\ ${ }^{5}$ Kwara State Universal Basic Education, Nigeria \\ nmadandola@yahoo.com
}

\begin{abstract}
Corona Virus Disease 2019 simply refers to as COVID-19 is among other coronaviruses that causes respiratory infections ranging from the common cold to more severe diseases. The virus was first outbreak in Wuhan, Hubei Province, China in December 2019 but Nigeria recorded its first incidence case in Lagos State on 27th of February 2020, at exactly a year 155,076 Nigerians were infected. Kwara State of Nigeria has 2,901 confirmed laboratory tested cases, 2,268 already discharged and 51 people confirmed dead cases within a year. Interviews were conducted for selected staff and students in Kwara state. The pandemic emergence has both consequences on the educational development of Kwara state with more negative consequences like contributing to decadence of the inadequate education materials as a result of schools' lockdown, health challenges, prolong of graduating years among others.
\end{abstract}

Keywords: coronavirus; educational; consequences; emergence; social distance

\section{Introduction}

Coronaviruses are a great family of viruses which may cause illness in animals or humans. Human coronaviruses were first identified in the mid-1960s (www.cdc.gov/coronavirus/types.html, 2020). In humans, quite a lot of coronaviruses are acknowledged to cause respiratory infections ranging from the common cold to more severe diseases such as Middle East Respiratory Syndrome (MERS) and Severe Acute Respiratory Syndrome (SARS) (e, Wang \& Mao, 2020). The most recently discovered coronavirus is called COVID-19. COVID-19 is an acronym that stands for: CO-Corona, VI-Virus, D-Disease, 19-2019. Corona is singular while Coronae are plural. It is a crown bestowed among the Roman as a reward for distinguished services. Biologically, it is a crown like appendage of a plant or animal, see figure 1.

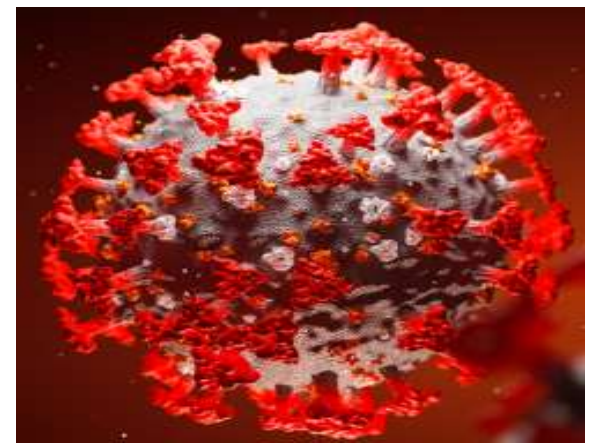

Figure 1. Structure of Corona (Andersen, Rambaut, Lipkin, Holmes \& Garry, 2020) 
There are seven coronaviruses that can infect people (Andersen, Rambaut, Lipkin, Holmes \& Garry, 2020). They are:

i. 229E (alpha coronavirus)

ii. NL63 (alpha coronavirus)

iii. OC43 (beta coronavirus)

iv. HKU1 (beta coronavirus)

v. MERS-CoV (the beta coronavirus that causes Middle East Respiratory Syndrome)

vi. SARS-CoV (the beta coronavirus that causes severe acute respiratory syndrome)

vii. SARS-CoV-2 (the novel coronavirus that causes coronavirus disease 2019, or COVID-19

A novel coronavirus outbreak was first documented in Wuhan, Hubei Province, China in December 2019, but rapidly spread to over 210 countries in the globe including Nigeria within two months. It has since spread worldwide, leading to an ongoing pandemic. The virus spread exponentially country by country and region by region rapidly affecting all daily life, in particular global healthcare systems, economy and education (Mohammad, 2020).

Nigeria confirmed its first case of coronavirus (COVID-19) in Lagos State on 27th of February 2020. The patient is an Italian citizen who works in Nigeria but returned from Milan, Italy to Lagos. As of Saturday February 27, 2021, 08:41 GMT, infection figures in Nigeria stood at 155,076 (Ebuka, February 27, 2021).

In April 6, 2020 Kwara announced her recorded first index cases $\{$ two $\}$ that was confirmed on Thursday 2nd of April, 2020 (@followKWSG.April 6,2020). As of October 6, 2020 (6 months later) 12 out of 16 Local Government Areas (LGAs) of Kwara state were infected with 1,049 total confirmed cases of which Irepodun having 4 cases. In January 9th, 2021 the total laboratory confirmed COVID-19 cases in Nigeria was 70,495 while Kwara State confirmed cases rose to 1,495. Exactly a year precisely Saturday February 27, 2021, 08:41 GMT, Kwara State of Nigeria has 2,901 confirmed laboratory tested cases, 2,268 already discharged and 51 people confirmed dead (Ebuka, February 27, 2021).

The supreme public signs of COVID-19 are fever, dry cough, tiredness, aches \& pains, headache, conjunctivitis, sore throat, diarrhoea, loss of taste or smell or a rash on skin or discoloration of fingers or toes (Centers for Disease Control and Prevention, November 2020). These signs are commonly trivial and activate slowly. Symptoms begin one to fourteen days after exposure to the virus. Around one in five infected individuals do not develop any symptoms (European Centre for Disease Prevention and Control, 2020).

A lot of infected persons (about 80\%) recover from the disease without going to hospital for treatment. Approximately 1 out of every 5 persons who infected with COVID-19 becomes extremely ill and develops difficulty in breathing. Aged citizens and those with medical challenges like cancer, diabetes, high blood pressure, heart problems, diabetes, or HIV are at higher risk of developing severe illness.

The pandemic affected all sectors in the world including Nigeria. The education sector also got its own fair share of the crisis with all schools closed. The COVID-19 pandemic has affected educational systems worldwide, leading to the near-total closures of schools, universities and colleges. The COVID-19 pandemic has affected more than $91 \%$ of students worldwide, with approximately 1.6 billion children and youngsters unable to attend physical schools due to temporary closures and lockdowns (UNICEF, 2020).

Due to the COVID-19 pandemic, many schools began conducting classes via videotelephony software such as Zoom. UNESCO recommends the use of distance learning programmes and open educational applications and platforms that schools and teachers can use to reach learners remotely and limit the disruption of education. 


\section{Research Methods}

The researchers adopted interview method to obtain information from students in two selected higher institutions in Kwara State. Twenty staff and One hundred students were interviewed at random from both Kwara State College of Education, Oro and Kwara State Polytechnic, Ilorin for the study. The simple frequencies distribution and column chart were used to analyse the information.

\section{Discussion}

\subsection{Confirmed Cases in Nigeria}

As of Saturday February 27, 2021, 08:41 GMT, NCDC confirmed that the total confirmed COVID 19 cases in Nigeria were 155,076, people on the admission were 20,608, people discharged were 132,566 and 1,902 were dead as a result of the COVID 19 (Ebuka, February 27, 2021). Nearly half of Nigeria's COVID-19 infections were recorded this year with about 70,000 infections reported since January 1, 2021 (Ebuka, February 27, 2021). Table1 shows COVID 19 break down per state within a year in Nigeria.

Table 1. Confirmed Cases per State (NCDC data: Ebuka, February 27, 2021)

\begin{tabular}{|c|l|c|c|c|c|}
\hline S/N & $\begin{array}{c}\text { States } \\
\text { Affected }\end{array}$ & $\begin{array}{c}\text { No. of Cases (Lab } \\
\text { Confirmed) }\end{array}$ & $\begin{array}{c}\text { No. of Cases (on } \\
\text { admission) }\end{array}$ & $\begin{array}{c}\text { No. } \\
\text { Discharged }\end{array}$ & $\begin{array}{c}\text { No. of } \\
\text { Deaths }\end{array}$ \\
\hline 1 & Lagos & 55,550 & 2,112 & 53,031 & 407 \\
\hline 2 & FCT & 19,186 & 7,208 & 11,834 & 144 \\
\hline 3 & Plateau & 8,874 & 99 & 8,718 & 57 \\
\hline 4 & Kaduna & 8,453 & 230 & 8,161 & 62 \\
\hline 5 & Oyo & 6,717 & 1,006 & 5,601 & 110 \\
\hline 6 & Rivers & 6,436 & 264 & 6,078 & 94 \\
\hline 7 & Edo & 4,529 & 517 & 3,846 & 166 \\
\hline 8 & Ogun & 4,377 & 774 & 3,557 & 46 \\
\hline 9 & Kano & 3,732 & 185 & 3,443 & 104 \\
\hline 10 & Ondo & 2,968 & 831 & 2,080 & 57 \\
\hline 11 & Kwara & 2,901 & 582 & 2,268 & 51 \\
\hline 12 & Delta & 2,556 & 747 & 1,744 & 65 \\
\hline 13 & Osun & 2,392 & 417 & 1,925 & 50 \\
\hline 14 & Nasarawa & 2,212 & 1,826 & 373 & 13 \\
\hline 15 & Gombe & 2,040 & 115 & 1,882 & 43 \\
\hline 16 & Katsina & 2,029 & 32 & 1,970 & 27 \\
\hline 17 & Enugu & 2,000 & 106 & 1,865 & 29 \\
\hline 18 & Ebonyi & 1,864 & 286 & 1,547 & 31 \\
\hline 19 & Anambra & 1,641 & 207 & 1,415 & 19 \\
\hline 20 & Abia & 1,514 & 67 & 1,427 & 20 \\
\hline 21 & Akwa Ibom & 1,484 & 643 & 827 & 14 \\
\hline 22 & Imo & 1,464 & 173 & 1,263 & 28 \\
\hline 23 & Borno & 1,266 & 164 & 1,064 & 38 \\
\hline 24 & Bauchi & 1,224 & 11 & 1,196 & 17 \\
\hline 25 & Benue & 1,188 & 575 & 591 & 22 \\
\hline 26 & Niger & 912 & 478 & 417 & 17 \\
\hline 27 & Taraba & 804 & 146 & 636 & 22 \\
\hline 28 & Ekiti & 788 & 124 & 654 & 10 \\
\hline & & & & \\
\hline
\end{tabular}




\begin{tabular}{|c|c|c|c|c|c|}
\hline 29 & Sokoto & 769 & 1 & 740 & 28 \\
\hline 30 & Bayelsa & 767 & 35 & 706 & 26 \\
\hline 31 & Adamawa & 762 & 470 & 264 & 28 \\
\hline 32 & Jigawa & 496 & 56 & 429 & 11 \\
\hline 33 & Kebbi & 365 & 51 & 300 & 14 \\
\hline 34 & Cross River & 324 & 57 & 254 & 13 \\
\hline 35 & Yobe & 268 & 17 & 242 & 9 \\
\hline 36 & Zamfara & 219 & -4 & 215 & 8 \\
\hline 37 & Kogi & 5 & 0 & 3 & 2 \\
\hline \multicolumn{2}{|c|}{ TOTAL } & 155,076 & 20,608 & 132,566 & 1,902 \\
\hline
\end{tabular}

Figure 2 revealed the number of laboratory confirmed cases in Nigeria within a year of infection. It was shown that Lagos State has the highest confirmed cases of 55,550, followed by FCT with 19,186 cases, Kwara state was ranked $11^{\text {th }}$ with 2,901 confirmed cases and Kogi State has the least confirmed cases of 5.

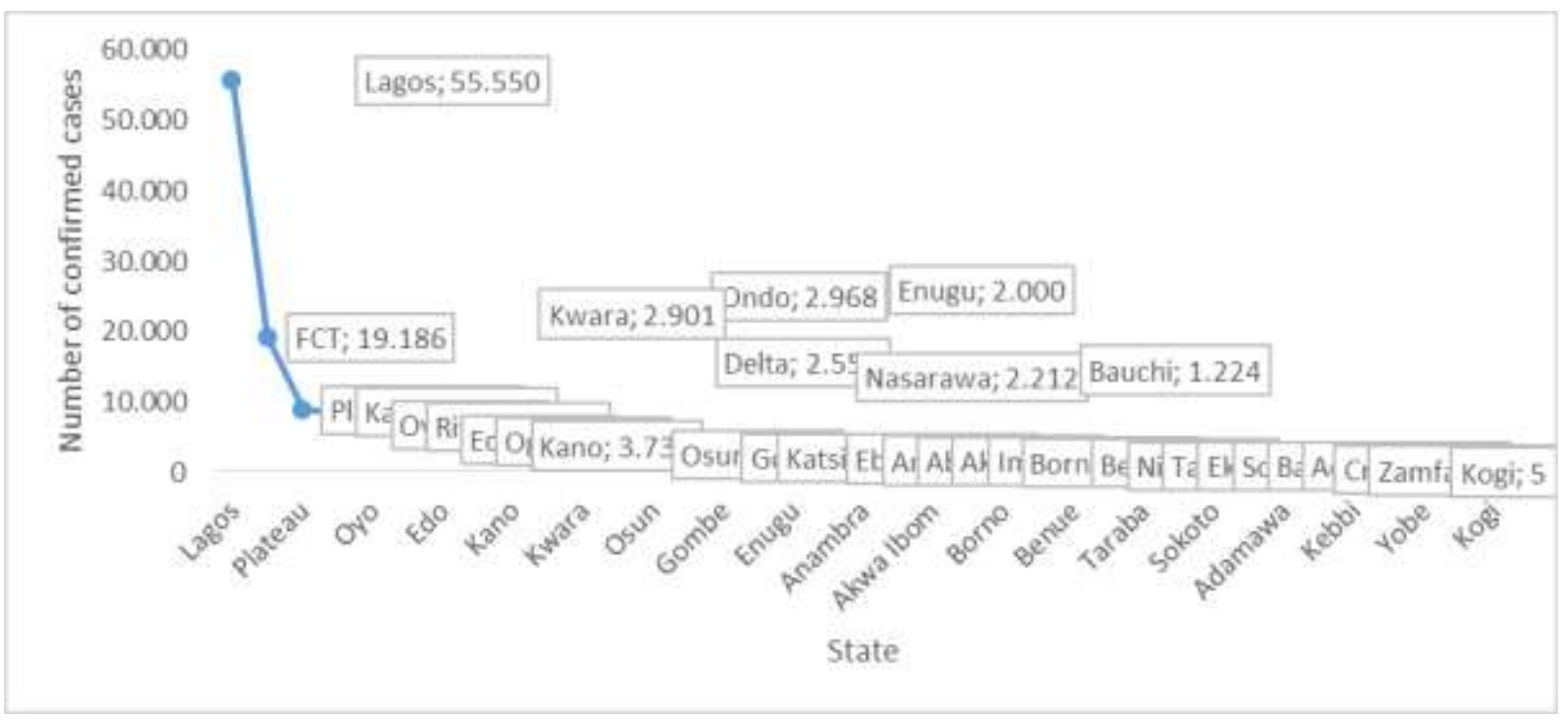

Figure 2. Lab Confirmed Cases in Nigeria per State

The number of deaths cases recorded within a 365 days in Nigeria was clearly shown in Figure 3. It was shown that Lagos State has the highest death tolls cases of 407 which is $0.73 \%$ of the Lab confirmed cases, the next state is Edo with 166 death cases amounting to $3.67 \%$ of the state laboratory confirmed cases, Kwara state was in $11^{\text {th }}$ position with record of 51 death cases which is $1.76 \%$ of the state confirmed lab cases and Kogi state has the least death cases of 2 which is $40 \%$ of the total confirmed cases in Kogi. Despite that Lagos state has the highest Laboratory and deaths cases it is still in the manageable and better control side than majority of states when comparing their death cases percentage. 


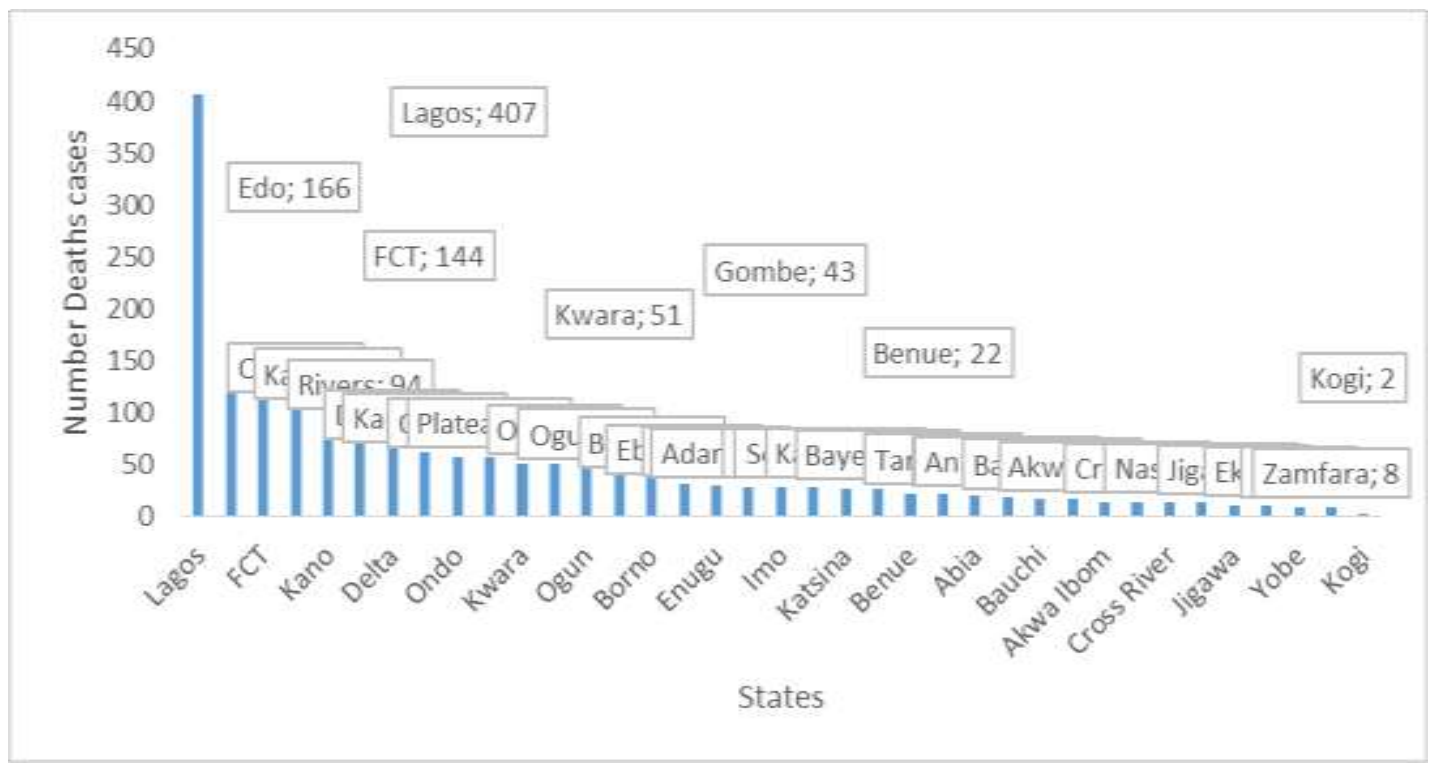

Figure 3. Confirmed Deaths Cases in Nigeria per State

\subsection{Preventive Measure for COVID-19}

Preventive measures to reduce the chances of infection include:

\section{Vaccine}

The first COVID-19 vaccine was granted regulatory approval on 2nd December, 2020 by the UK medicines regulator MHRA (Medicines and Healthcare Products Regulatory Agency, 2020). A COVID-19 vaccine is a vaccine intended to provide acquired immunity against COVID-19. National regulatory authorities have approved six vaccines for public use:

a. Two RNA vaccines (tozinameran from Pfizer-BioNTech and mRNA 1273 from Moderna),

b. Two conventional inactivated (BBIBP-CorV from Sinopharm and CoronaVac from Sinovac),

c. Two viral vector vaccines (Gam-COVID-Vac from the Gamaleya Research institute and AZD1222 from the University of Oxford and AstraZeneca) (Santiago, 2020).

\section{Social Distancing}

Social distancing (also known as physical distancing) embraces infection control actions anticipated to dawdling the spread of the disease by minimising close contact between individuals. Individuals may apply social distancing methods by staying at home, limiting travel, avoiding crowded areas, using no-contact greetings, and physically distancing themselves from others (Ward, 2020). Initial recommendations included maintaining a two-meter distance from others outside the family unit. In late March 2020, the WHO and other health bodies began to replace the use of the term "social distancing" with "physical distancing", to clarify that the aim is to reduce physical contact while maintaining social connections, either virtually or at a distance. Outbreaks have occurred in prisons due to crowding and an inability to enforce adequate social distancing (Waldstein, 2020). It is a measure without negative health side effect. 


\section{Self-isolation}

Self-isolation at home has been endorsed for those detected with COVID-19 and those who suspect they have been infected. Health agencies have issued detailed instructions for proper self-isolation. Many governments have mandated or recommended self-quarantine for entire populations. The strongest self-quarantine instructions have been issued to those in high-risk groups (COVID-19 Informational Resources for High-Risk Groups, 2020). Those who may have been exposed to someone with COVID-19 and those who have recently travelled to a country or region with the widespread transmission have been advised to selfquarantine for 14 days from the time of last possible exposure.

\section{Face Masks and Respiratory Hygiene}

The WHO advises persons to wear non-medical face coverings in public settings where there is an increased threat of diffusion and where physical distancing measures are difficult to maintain (Reuters. 2020). Face coverings limit the volume and travel distance of expiratory droplets dispersed when talking, breathing, and coughing (ECDC. 2020.). Face coverings also sieve out particles containing the virus from inhaled air, reducing the chance that the wearer will become infected (Centers for Disease Control and Prevention, November 2020.). Masks are also strongly recommended for those who may have been infected and those taking care of someone who may have the disease (Centers for Disease Control and Prevention, February 2020). The CDC and WHO recommend covering the mouth and nose with a tissue paper when face mask is not available or using the inside of the elbow when tissue paper is not available when coughing or when sneezing (World Health Organization, August 2020).

\section{Hand-Washing and Hygiene}

Proper hand hygiene after any cough or sneeze is encouraged (Centers for Disease Control and Prevention, February 2020). The WHO also recommends that individuals wash hands often with soap and water for at least 20 seconds, especially after going to the toilet or when hands are visibly dirty, before eating and after blowing one's nose (World Health Organization, August 2020).

\section{Alcohol-Based Hand Sanitiser}

The CDC recommends using an alcohol-based hand sanitiser with at least 60\% alcohol, but only when soap and water are not readily available (nhs.uk. June 2020).

\section{Surface Cleaning}

Coronaviruses on surfaces die "within hours to days". Coronaviruses die faster when exposed to sunlight and warm temperatures.

\section{The CDC}

The CDC recommends that if a COVID-19 case is suspected or confirmed at a facility such as an office or day care, all areas such as offices, bathrooms, common areas, shared electronic equipment like tablets, touch screens, keyboards, remote controls, and ATM machines used by the ill persons should be disinfected (Centers for Disease Control and Prevention, February 2020.). 


\section{Ventilation and Air Filtration}

The WHO recommends ventilation and air filtration in public spaces to help clear out infectious aerosols (Somsen, van Rijn, Kooij, Bem, \& Bonn, 2020).

\section{Healthy Diet and Lifestyle}

COVID-19 has made the maintenance of one's immune system more important than ever (Harvard, 2020). It therefore recommends a healthy diet, being physically active, managing psychological stress, and getting enough sleep. Dark-skinned people are at particular risk of a vitamin D deficiency which can impair the immune system (Harvard, 2020).

\subsection{Consequence of COVID-19 on Educational Development}

Coin is with two sides, thus the emergence of COVID-19 has positive and negative consequences.

a. Some Positive consequences of COVID-19 on Educational Development

i. COVID-19 exposes Lecturers and students to field of I.T such as virtual learning

ii. It boosts media lesson and reduced media phobia

iii. There is improvement in E-book usage among students and Lecturers

iv. It promotes distance learning programmes

\section{b. Some Negative Consequences of COVID-19 on Educational Development}

i. COVID-19 destabilizes Kwara State academic calendar. For instance; in Kwara State College of Education, Oro those students (NCE III) students that ought to have graduated since first week of August 2020 graduated in January 2021.

ii. It causes setback for all the of students' career. For example, Kwara State Polytechnics, Ilorin students that ought to be enrolled for National Youth Service Corps were denied the opportunity as a result of pandemic.

iii. Many of the students' academic abilities were affected negatively, students Intelligent Quotient were retarded (Start over again syndrome).

iv. There is decadence of the already inadequate educational equipment e.g furniture, scientific reagents in the colleges /schools.

v. The introduction of E-learning as a result of COVID-19 causes physical discomfort on both students and staff as a result of long usage of computer.

vi. Data insecurity when uploading data or educational resources to web spaces

vii. It contributed to Eye Disorder of students and lecturers. Many of staff and students of Kwara State especially in higher institutions are now using glasses. Small fonts that are displayed on the computer/phone screen and the rays are sometimes too bright for the eyes (Wahid, Pribadi \& Wakas, 2020)

viii. The adoption of virtual learning Triggers Neck Pain, back pain as a result of bent position of neck and back. In severe conditions, the habit of bending for too long can also cause shoulders, and arms pains (Wahid, Pribadi \& Wakas, 2020).

ix. It leads to closure of some private schools which usually assist in education development in our areas. Many of the private schools could not meet up the measures put in place by the government to re-open schools. Many of the teachers that could not pay salary during the lockdown left the schools and contributing to temporary closed down due to lack of teachers. 


\section{Conclusion and Suggestion}

\subsection{Conclusion}

Emergence of COVID-19 in Nigeria within a year has caused havoc to many sectors of human endeavor worldwide in which Education is not left behind. No wonder it was declared as Pandemic. Its negative effects on Kwara state educational development is worrisome. Millions of students were out of schools, decadence of the inadequate education materials as a result of schools' lockdown, prolonging the graduating years of our children among others.

\subsection{Suggestion}

It is highly recommended that:

i. All stakeholders in educational sectors should know that COVID-19 is REAL and lockdown as a result of COVID-19 caused much havoc to education so COVID19 preventive measures must be obeyed.

ii. Virtual class is not an alternative to physical class due to its resultant negative health challenges on teachers and students.

iii. Government should provide enough spaces, facilities and teachers for physical distancing which is the best preventive measure even without negative health consequences.

\section{References}

Andersen, K.G., Rambaut, A., Lipkin, W.I., Holmes, E.C., \& Garry, R. F. (2020). "The proximal origin of SARS-CoV-2". Nature Medicine. 26 (4): 450-452. doi:10.1038/s41591-020-0820-9. PMC 7095063. PMID 32284615.

Centers for Disease Control and Prevention (CDC) (10 November 2020). "Scientific Brief: Community Use of Cloth Masks to Control the Spread of SARS-CoV-2". U.S.

Centers for Disease Control and Prevention (CDC) (11 February 2020). "Coronavirus Disease 2019 (COVID-19)". U.S. Retrieved 6 December 2020.

Centers for Disease Control and Prevention (CDC) (11 February 2020). "Interim Recommendations for US Community Facilities with Suspected/Confirmed Coronavirus Disease 2019". U.S. Retrieved 4 April 2020.

COVID-19 Informational Resources for High-Risk Groups | Keeping Education ACTIVE | Partnership to Fight Chronic Disease". fightchronicdisease.org. Retrieved 31 May 2020.

E, Q., Wang, B., \& Mao, J. (June 2020). "The pathogenesis and treatment of the 'Cytokine Storm' in COVID-19". The Journal of Infection. 80 (6): 607-613. 10.1016/j.jinf.2020.03.037. PMC 7194613. PMID 32283152.

Ebuka, O. (February 27, 2021). 'PREMIUM TIMES'. www.premiumtimesng.com

ECDC. (8 April 2020). "Using face masks in the community - Technical Report" (PDF).

European Centre for Disease Prevention and Control (2020). "Transmission of COVID19". Retrieved 6 December 2020.

Harvard, T. H. (29 May 2020). "Food safety, nutrition, and wellness during COVID-19". Chan School of Public Health. Retrieved 8 November 2020.

https://www.cdc.gov/coronavirus/types.htmlreviewed: February 15, 2020

https://covid19.ncdc.gov.ng/

Medicines and Healthcare Products Regulatory Agency (2020). "Government of the UK medicines regulator gives approval for first UK COVID-19 vaccine",. Retrieved 2 December 2020.

Mohammad, Hossein Keshavarz (August 2020). A Proposed Model for Post-Pandemic 
Higher Education . Budapest International Research and Critics in Linguistics and Education (BirLE)Journal. 3( 3). 1384-1391. www.bircu-journal.com/index.php/birle Nhs.uk. (2 June 2020). "Social distancing: what you need to do-Coronavirus (COVID19)". Retrieved 18 August 2020.

Reuters, (2020). "Wear masks in public says WHO, in update of COVID-19 advice". Retrieved 3 July 2020.

Santiago, Jahleah (2020). "A side-by-side comparison of the Pfizer/BioNTech and Moderna vaccines". STAT. Retrieved 24 December 2020.

Somsen, G.A., van Rijn, C., Kooij, S., Bem, R.A., \& Bonn, D. (July 2020). "Small droplet aerosols in poorly ventilated spaces and SARS-CoV-2 transmission". The Lancet. Respiratory Medicine. Elsesier. 8 (7):658-659. doi:10.1016/S2213-2600(20)302459.PMC 7255254. PMID 32473123.

United Nations International Children's Fund (UNICEF) June 112020

Wahid, R., Pribadi,F., \& Wakas, B. E. (August 2020). Digital Activism: Covid-19 Effects in Campus of Learning. Budapest International Research and Critics Linguistics and Education (BirLE Journal): Linguistics and Education Science, P-ISSN 2655-2647, 3(3), 1336-1342.

Waldstein, D. (6 May 2020). "To Fight Virus in Prisons, C.D.C. Suggests More Screenings". The New York Times. Retrieved 14 May 2020.

Ward, A. (2020). "Has Sweden found the best response to the coronavirus? Its death rate suggests it hasn't". Vox. Retrieved 30 April 2020.

World Health Organization (WHO) (2020). "Advice for the public on COVID-19 ". Retrieved 18 August 2020. 